\title{
Occurrence and profiling of multiple nitrosamines in source water and drinking water of China
}

\author{
Wanfeng Wang a,b , Jianwei Yu ${ }^{\text {a,* }}$, Wei An ${ }^{a}$, Min Yang ${ }^{a}$

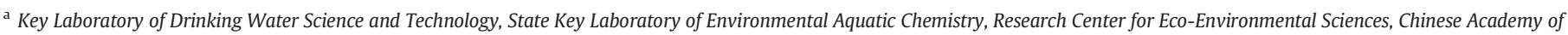 \\ Sciences, Beijing 100085, China

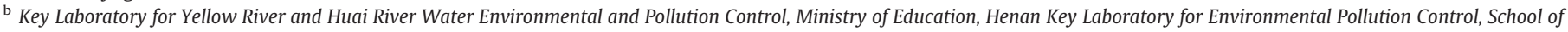 \\ Environment, Henan Normal University, Xinxiang 453007, China
}

\section{H I G H L I G H T S}

- Studied the occurrence of multiple nitrosamines in 54 DWTPs across major cities of China.

- NDMA, NDEA and NDBA were the most abundant in DWTPs, and the detection frequencies in source waters were even higher than those in finished waters.

- The three main nitrosamines posed a cancer risk of $2.99 \times 10^{-5}$ to the local populations due to their occurrence in drinking water.

\section{G R A P H I C A L A B S T R A C T}

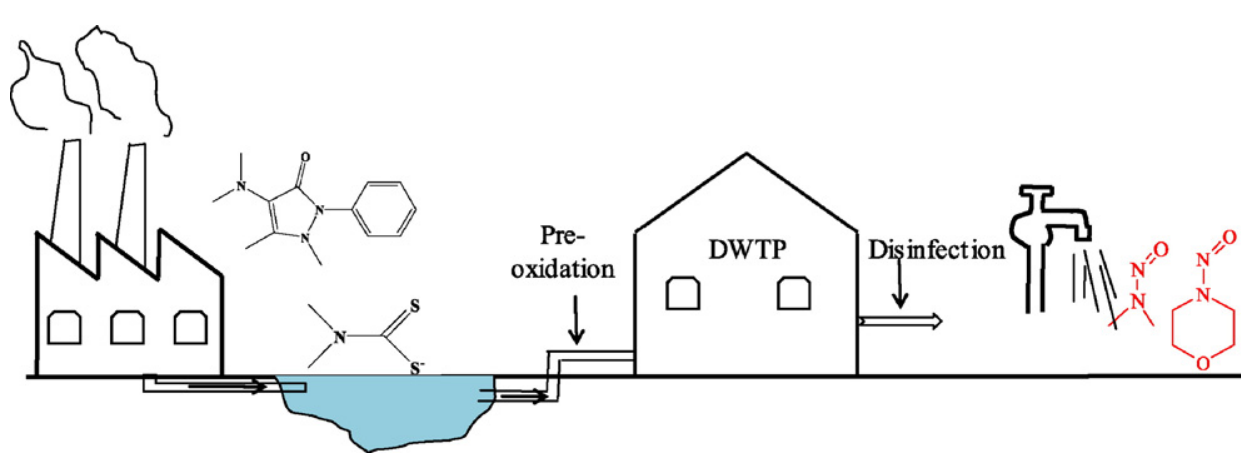

\begin{abstract}
A B S T R A C T
The occurrence of multiple nitrosamines was investigated in 54 drinking water treatment plants (DWTPs) from 30 cities across major watersheds of China, and the formation potential (FP) and cancer risk of the dominant nitrosamines were studied for profiling purposes. The results showed that N-nitrosodimethylamine (NDMA), $\mathrm{N}$-nitrosodiethylamine (NDEA) and N-nitrosodi-n-butylamine (NDBA) were the most abundant in DWTPs, and the concentrations in source water and finished water samples were not detected (ND) $-53.6 \mathrm{ng} / \mathrm{L}$ (NDMA), $\mathrm{ND}-68.5 \mathrm{ng} / \mathrm{L}(\mathrm{NDEA}), \mathrm{ND}-48.2 \mathrm{ng} / \mathrm{L}$ (NDBA). The frequencies of detection in source waters were $64.8 \%$, $61.1 \%$ and $51.8 \%$, and $57.4 \%, 53.7 \%$, and $37 \%$ for finished waters, respectively. Further study indicated that the FPs of the three main nitrosamines during chloramination were higher than those during chlorination and in drinking water. The results of Principal Components Analysis (PCA) showed that ammonia was the most closely associated factor in nitrosamine formation in the investigated source water; however, there was no significant correlation between nitrosamine-FPs and the values of dominant water-quality parameters. The advanced treatment units (i.e., ozonation and biological activated carbon) used in DWTPs were able to control the nitrosamine-FPs effectively after disinfection. The target pollutants posed median and maximum cancer risks of $2.99 \times 10^{-5}$ and $35.5 \times 10^{-5}$ to the local populations due to their occurrence in drinking water.
\end{abstract}

(c) 2016 Elsevier B.V. All rights reserved.

\footnotetext{
* Corresponding author.

E-mail address: jwyu@rcees.ac.cn (J. Yu).
}

\section{Introduction}

Considerable attention had been focused on the occurrence of nitrosamines, a class of widespread disinfection by-products (DBPs) 
and industrial by-products, because of their suspected carcinogenicity and mutagenicity, as well as the risk of stomach, esophageal, and nasopharyngeal cancers (Eichholzer and Gutzwiller, 1998). In particular, N-nitrosodimethylamine (NDMA) has been frequently detected in water resources in many countries, which could be mainly attributed to the use of chlorine, chloramine or ozone for the disinfection of drinking water or wastewater (Mitch et al., 2003; Sedlak et al., 2005; Pehlivanoglu-Mantas et al., 2006; Andrzejewski et al., 2008). It is estimated that concentrations of NDMA as low as $0.7 \mathrm{ng} / \mathrm{L}$ in drinking water would be associated with a $10^{-6}$ lifetime cancer risk; the corresponding concentration is $0.2 \mathrm{ng} / \mathrm{L}$ for $\mathrm{N}$-nitrosodiethylamine (NDEA) (US EPA, 2007). The International Agency for Research on Cancer (IARC) has classified NDMA and NDEA as probable carcinogens to humans (Group 2A), and six other nitrosamines including $\mathrm{N}$ nitrosomethylethylamine (NMEA), N-nitrosopyrrolidine (NPyr), Nnitrosomorpholine (NMor), N-nitrosopiperidine (NPip), N-nitrosodin-propylamine (NDPA), and N-nitrosodi-n-butylamine (NDBA) are classified as possible carcinogens to humans (Group 2B) (IARC, 1978).

As a group of emerging DBPs, nitrosamines have been detected in water treatment processes in many countries. NDMA has been widely investigated in drinking water in Canada (Zhao et al., 2008), the United States (Mitch et al., 2003), and Japan (Asami et al., 2009). The concentrations of NDEA have been reported in only several countries and regions, in drinking water (3.7-12.9 ng/L) (Jurado-Sanchez et al., 2010; Planas et al., 2008) and domestic wastewater $(0.132 \mu \mathrm{g} / \mathrm{L})$ (Hartmetz and Slemrova, 1980). Although other nitrosamines including NMEA, NDPA, NMor, NPip, NPyr, NDBA, and N-nitrosodiphenylamine (NDPhA) have been investigated in several drinking water treatment plants (DWTPs) (Wang et al., 2011) and a digestive system cancer region (Ma et al., 2012), due to the lack of a detailed national survey, information regarding the occurrence and concentration levels of multiple nitrosamines in different treatment types of DWTPs across major watersheds in China is still very limited. On the other hand, several studies have investigated the effects of different disinfection processes on nitrosamine formation. However, DBP formation is a complicated process that is influenced by many variables including the $\mathrm{pH}$, temperature, turbidity, natural organic matter (NOM) content and concentration in source water, the different types of pre-oxidation and filtrations, as well as the type and concentration of the disinfectants used and disinfection contact time. Some of the previous studies have evaluated the formation of NDMA during ozonation and pre-oxidation (Andrzejewski et al., 2008; Schmidt and Brauch, 2008). Pre-oxidation processes such as pre-chlorination, pre-chloramination and pre-ozonation are widely used in drinking water treatment (Susan et al., 2003; Rodgers, 1997; Camel and Bermond, 1998), leading to the formation of nitrosamines before filtration and disinfection processes. However, few previous reports have shown the relationship between the migration, transformation and control techniques of the multiple nitrosamines and the different types of treatment processes in DWTPs.

With the development of the economy and society, the water environment is becoming more and more complicated in China. The occurrence and fate of toxic compounds in China's DWTPs is necessary for study of their corresponding control techniques. Therefore, in the current study, a total of 54 source water and finished water samples from 30 cities across China were collected for a survey of multiple nitrosamines, and the dominant nitrosamine-FPs were analyzed during chlorination and chloramination. In addition, we made an attempt to estimate the cancer risk of the dominant nitrosamines in potable water for the local populations.

\section{Materials and methods}

\subsection{Sample collection}

The study areas and sampling sites are shown in Fig. 1. Source water and finished water samples were collected from 54 full-scale DWTPs of
30 cities in China between March and May 2010 (Spring), including the Songhua River basin, the Liao River basin, the Yellow River basin, the Yangtze River basin, and the Pearl River basin (Fig. 1). There were 24 source waters coming from rivers, 23 source waters were from reservoirs, and 7 source waters derived from groundwater. There was no rainfall during the sampling periods. The samples were collected in amber glass bottles and sodium thiosulfate $(20 \mathrm{mg} / \mathrm{L})$ was added to quench any chlorine residue. Then the samples were delivered under refrigerated conditions ( $4{ }^{\circ} \mathrm{C}$ in cooling boxes) within $48 \mathrm{~h}$ to the lab. Once they arrived in the lab, the samples were stored in the dark at $4{ }^{\circ} \mathrm{C}$ until they were analyzed. Information regarding the source water characteristics, disinfectants, and water treatment processes is shown in Supplementary Table A.

\subsection{Sample preparation for analyzing nitrosamines}

After filtration with a glass microfiber filter (GF/C, $1.2 \mu \mathrm{m}$; Whatman, Maidstone, UK), $0.5 \mathrm{~L}$ of water was adjusted to $\mathrm{pH} 8.0$ with about $1.0 \mathrm{~g}$ of solid sodium bicarbonate and spiked with $20 \mathrm{ng} / \mathrm{L}$ internal standard $\left(\right.$ NDMA- $\left.\mathrm{d}_{6}\right)$. The samples were extracted using Resprep EPA 521 cartridges ( $2 \mathrm{~g} / 6 \mathrm{~mL}$, Restek, Bellefonte, PA, USA) which had been preconditioned with $10 \mathrm{~mL}$ of hexane, $20 \mathrm{~mL}$ of dichloromethane, $20 \mathrm{~mL}$ of methanol, and $20 \mathrm{~mL}$ of water at a flow rate of $3-5 \mathrm{~mL} / \mathrm{min}$. Next, the cartridges were dried under a flow of nitrogen gas. After $20 \mathrm{~mL}$ of dichloromethane was used to elute each cartridge, $400 \mu \mathrm{L}$ of a water/methanol solution (95:5, $v / v)$ was added to the elutions, and the dichloromethane was completely removed using a rotary evaporator (LabTech, USA). Then the sample volume was gravimetrically adjusted to $0.5 \mathrm{~mL}$ using ultrapure water. To remove possible solid particles, all samples were filtered through syringe filters (GHP Acrodisc $13 \mathrm{~mm}, 0.2 \mu \mathrm{m}$, PALL) prior to injection into the UPLC-MS/MS system.

\subsection{Nitrosamine formation potential test for source waters}

To investigate the potential risks in drinking water, we studied the main nitrosamine-FPs of 41 source water samples in chlorination and chloramination. The $\mathrm{Cl}_{2}$-demand $\left(\mathrm{Cl}_{2}\right.$-D) and $\mathrm{NH}_{2} \mathrm{Cl}$-demand $\left(\mathrm{NH}_{2} \mathrm{Cl}\right.$ D) were measured according to our previous study (Wang et al., 2011). The samples were chlorinated and chloraminated in $500 \mathrm{~mL}$ amberized vials by keeping a free chlorine or chloramine residual of $1.0 \mathrm{mg} / \mathrm{L}$ after storage at $(25 \pm 1){ }^{\circ} \mathrm{C}$ for $24 \mathrm{~h}$. Analyses of nitrosamine were then conducted after the residual chlorine and chloramine were quenched. The $\mathrm{Cl}_{2}$-D and $\mathrm{NH}_{2} \mathrm{Cl}-\mathrm{D}$ for 41 source waters are listed in Supplementary Table B.

\subsection{UPLC-ESI-MS/MS analysis for nitrosamines}

Nitrosamine analysis followed our previous method (Wang et al., 2011). Briefly, the LC apparatus was an Acquity Ultra performance LC (Waters, USA). All analytes were separated using a Waters Acquity ultra-performance liquid chromatography (UPLC) $\mathrm{BEH} \mathrm{C}_{18}$ column (150 mm $\times 2.1 \mathrm{~mm}, 1.7 \mu \mathrm{m}$ particle size; Waters, USA). Methanol (A) and ultrapure water containing $10 \mathrm{mmol} / \mathrm{L}$ ammonium bicarbonate (B) were used as mobile phases. Mass spectrometry was performed using a Premier XE tandem quadrupole mass spectrometer (Waters) equipped with a Z-Spray ionization (ESI) source. ESI-MS/MS detections were performed in the positive ion mode, and quantitative analysis was performed in the multiple reaction monitoring (MRM) mode. Recoveries and method detection limits (MDLs) of nine nitrosamines in various types of aqueous matrices are shown in Supplementary Table C.

\subsection{Statistical analysis}

Principal component analysis (PCA) between source water quality variables and the sum FPs of the three main nitrosamines were performed. The water quality parameters of 41 source waters included 


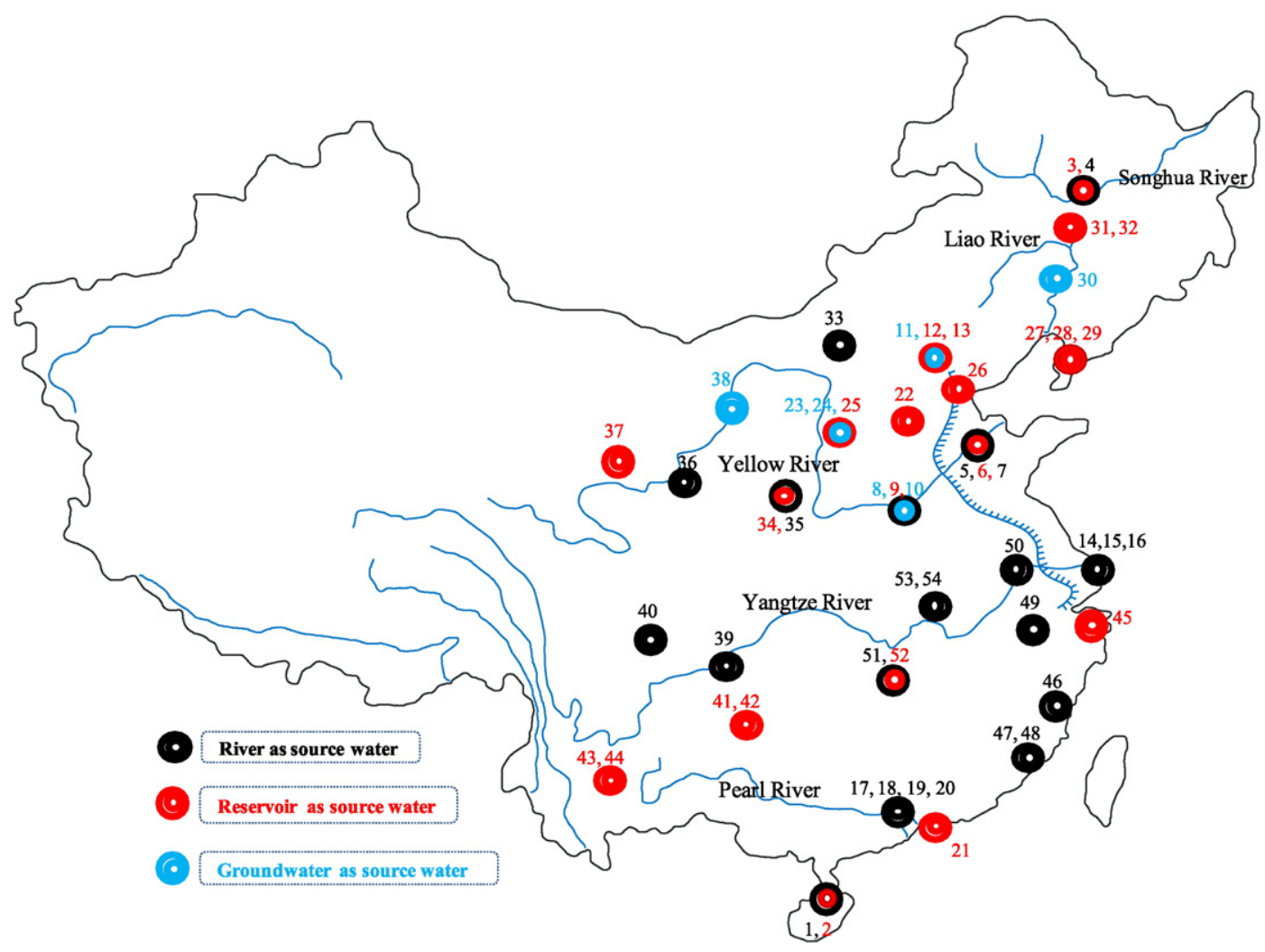

Fig. 1. Map of sampling locations of DWTPs in China (The sequence number of DWTPs: 1-54).

$\mathrm{NH}_{3}-\mathrm{N}, \mathrm{NO}_{3}^{-}-\mathrm{N}, \mathrm{NO}_{2}^{-}-\mathrm{N}, \mathrm{DOC}$, and $\mathrm{UV}_{254}$. The sum FPs were the formation potential of the three dominant nitrosamines in 41 source water under chloramination, and the three nitrosamines were NDMA, NDEA and NDBA. All statistical analyses were performed with SPSS 17.0 .

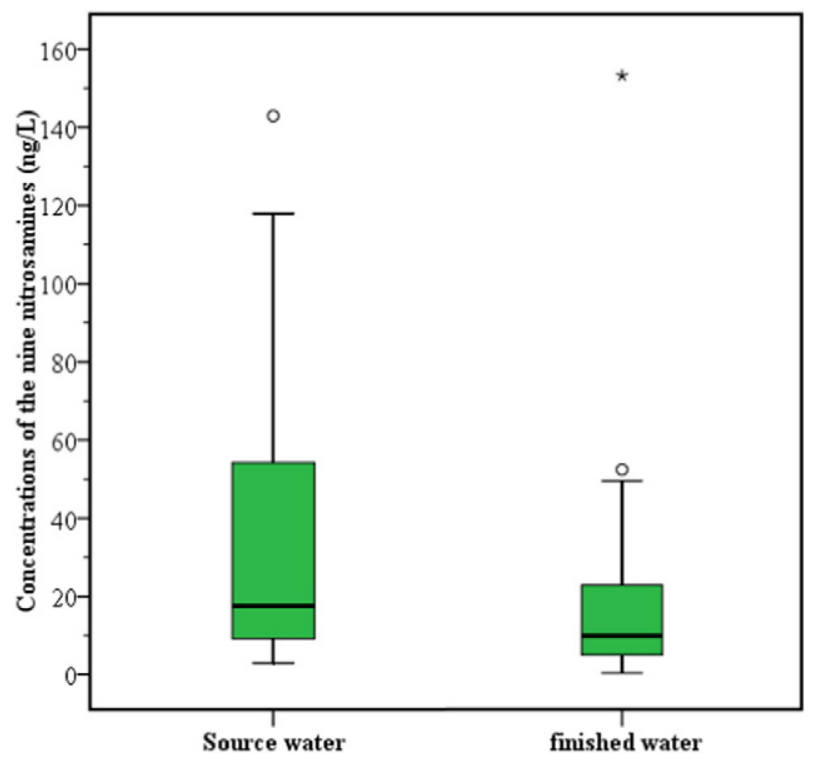

Fig. 2. Concentrations of the nine nitrosamines in source water and finished water samples in 54 DWTPs.

\section{Results and discussion}

\subsection{Occurrence of multiple nitrosamines in source water and finished water}

Nine nitrosamines including NDMA, NMEA, NDEA, NDPA, NMor, NPyr, NPip, NDBA, and NDphA were detected in source water and finished water samples collected from 54 DWTPs as shown in Fig. 2. The median and maximum concentrations of the nine nitrosamines in source water samples were 17.5 and $142.9 \mathrm{ng} / \mathrm{L}$, respectively (Supplementary Table D). Of the 54 sites, NDMA was detected in 35 source water samples, with concentrations ranging from 2.9 to $53.6 \mathrm{ng} / \mathrm{L}$,

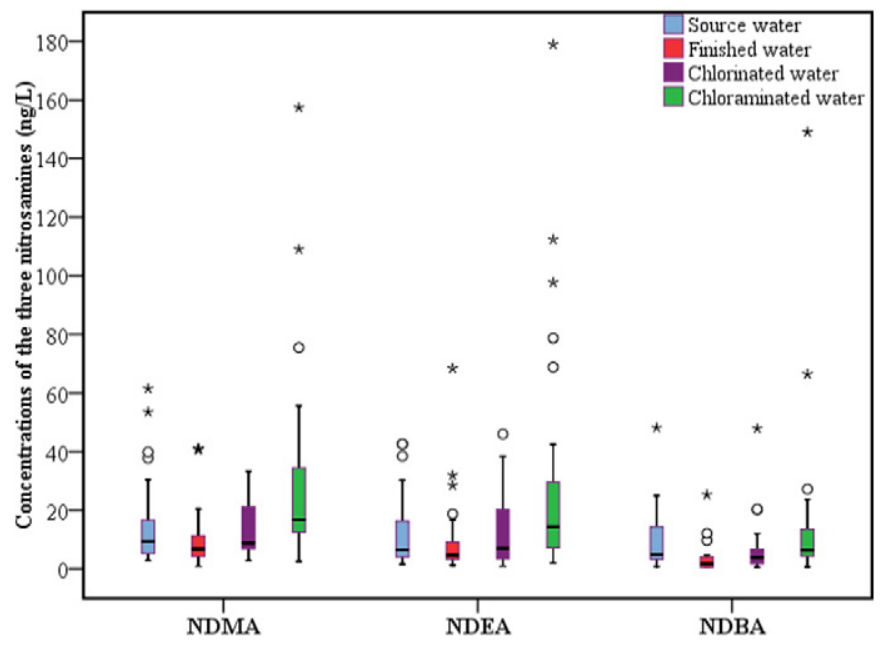

Fig. 3. Concentrations and formation potentials of the main nitrosamines in source water and finished water samples. 
NDEA (1.2-42.6 ng/L) and NDBA (0.8-48.2 ng/L) were detected in 33 and 28 source water samples (Fig. 3 and Supplementary Table C). The detection frequencies of the three nitrosamines were $64.8 \%, 61 \%$ and $51.9 \%$, respectively. The detection frequencies of six other nitrosamines in source water samples including NMEA, NDPA, NMor, NPyr, NPip and NDphA were $20.4 \%, 14.8 \%, 25.9 \%, 13 \%, 16.7 \%$, and $16.7 \%$, respectively, and the concentrations were 1.2-12.7, 2.8-9.7, 0.8-23.5, 1.1-12.6, 3.312.3 , and 2.8-8.4 ng/L, respectively. Relatively high contributions of NDMA (33.3\%), NDEA (27.8\%) and NDBA (17.5\%) in source water samples to the total nitrosamines were observed (Fig. 3). Occurrence of the three main nitrosamines was also reported in some DWTPs in the previous China survey (Wang et al., 2011), however, the maximum concentrations in the current study were much higher. The concentrations of NDEA (up to $42.6 \mathrm{ng} / \mathrm{L}$ ), which has a much higher carcinogenic potential $\left(10^{-6}\right.$ lifetime cancer risk level: $\left.0.2 \mathrm{ng} / \mathrm{L}\right)$ than NDMA $(0.7 \mathrm{ng} / \mathrm{L})$ in the quantitative estimate of carcinogenic risk from drinking water (US EPA, 2007), were even higher than those in DWTPs in China (1.9$16.3 \mathrm{ng} / \mathrm{L}$ ) (Wang et al., 2011) and in 20 sewage treatment plants (STPs) in Switzerland (up to $25 \mathrm{ng} / \mathrm{L}$ ) (Krauss et al., 2009).

The occurrence of these chemicals in source water, especially NDMA, NDEA and NDBA, is significantly different from previous investigations showing very low concentrations in source waters of other countries. Most of these surveys indicated that only NDMA but no other nitrosamines was detected with lower concentrations, such as in Southeastern America (<MDL) (Uzun et al., 2015) and North America (up to $9.4 \mathrm{ng} / \mathrm{L}$ ), Canada (Ontario, up to $8.0 \mathrm{ng} / \mathrm{L}$ ) (Barrett et al., 2003; Charrois et al., 2007; Qian et al., 2015), and Japan (up to $4.3 \mathrm{ng} / \mathrm{L}$ ) (Asami et al., 2009); besides that, Zhao et al. (2008) ever reported higher concentrations of NDMA occurrence in six source waters from Canada and the United States (up to $53 \mathrm{ng} / \mathrm{L}$ ). The results in our survey indicated the presence of extensive discharge sources. Previous studies have shown that NDMA may be present in secondary effluents from sewage treatment systems and in effluents from industries including rubber, leather, pesticides, food processing, foundries and dyes (Chen and Young, 2008; Feng et al., 2009). NDEA, NDBA, NMor and NDPhA have been detected in emulsion products, such as condoms, baby bottle nipples, rubber, soothers and gloves, and in tobacco, meat and wines (Thilen and Shishoo, 2000; Verna et al., 1996). The industrial by-products and domestic discharge containing nitrosamines might be one major source for the investigated source waters. To our knowledge, this is the first comprehensive and detailed report concerning the occurrence of nitrosamines other than NDMA in DWTPs across China.

Regarding different types of source water, the higher concentrations of the three nitrosamines ( $>10 \mathrm{ng} / \mathrm{L}$ ) were mainly found in surface water, including 11 river waters (DWTPs 4, 14, 15, 16, 17, 18, 35, 49, $50,51,54$ ) and 8 reservoir waters (DWTPs $6,21,26,29,43,44,45$, 52 ). On the contrary, the concentrations of nitrosamines were notably lower in the 7 groundwater sources (DWTPs $8,10,11,23,24,30,38$ ) (Fig. 4). The relatively high concentrations of nitrosamines in river and reservoir water samples were perhaps related to the contamination of source water by industrial by-products, as indicated above. Among the 11 river water sources, the concentrations of the three nitrosamines in 6 source waters (DWTPs 4, 17, 18, 35, 51, and 54) were above $50 \mathrm{ng} / \mathrm{L}$, which was probably correlated to the contamination of source water as indicated by high DOC $(6.83,4.28,3.95,4.36$, and $3.16 \mathrm{mg} / \mathrm{L}$ for DWTPs $4,17,18,35$, and 54 , respectively), ammonia $(0.79,0.47$, and $0.45 \mathrm{mg} / \mathrm{L}$ for DWTPs 17,18 , and 54, respectively), and nitrate (10.9, 3.26, 3.01, 5.95, and $2.98 \mathrm{mg} / \mathrm{L}$ for DWTPs 4, 17, 18, 35, and 54, respectively) levels. In previous studies, relationship between nitrosamineFP and these water quality parameters has been observed (Chen and Young, 2008; Choi and Valentine, 2003). In addition, DWTPs 4, 17, 18, 35,51 , and 54 were located in the middle and downstream of the river sources, so contamination contributions from the industrial and domestic discharge of nitrosamines could not be neglected (Mitch et al., 2003; W.J. Zhou et al., 2009; Q. Zhou et al., 2009).

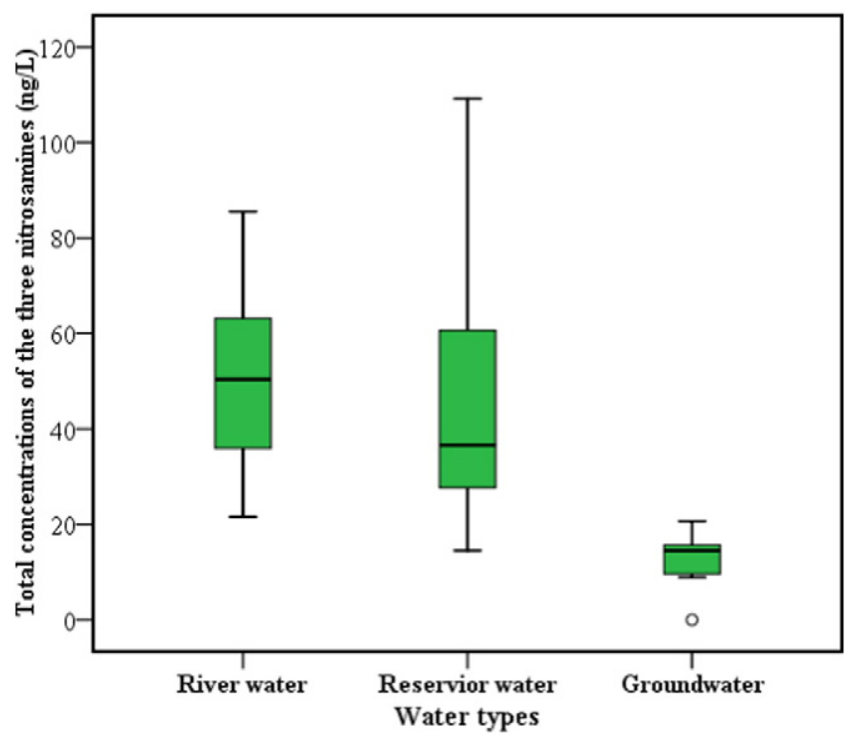

Fig. 4. Concentrations of the dominant nitrosamines (NDMA, NDEA, and NDBA) in different types of source water (river water, reservoir water, and groundwater).

The ratio of the sum concentrations of the nine nitrosamines in finished water to those in source water was $42.3 \%$ on the 75 th percentile value basis (Supplementary Table D); the median and maximum concentrations of the nine nitrosamines in this study were $9.95 \mathrm{ng} / \mathrm{L}$ and $153.2 \mathrm{ng} / \mathrm{L}$, respectively, which is similar to the US and Canada survey results. Compared to those in source water samples, the concentrations of NDMA in finished water samples ranged from 0.9 to $40.8 \mathrm{ng} / \mathrm{L}$; NDEA and NDBA were 1.6-68.5 ng/L and 0.4-25.3 ng/L, respectively (Fig. 3 and Supplementary Table C). The detection frequencies of the three nitrosamines were $57.4 \%, 53.7 \%$, and $37 \%$, respectively. In some DWTPs, the concentrations of NDMA increased from DWTPs 21 increased by $31.6 \mathrm{ng} / \mathrm{L}$ and those from 17 DWTPs (DWTPs 5, 7, 13, 16, 18, 19, 20, $21,27,31,33,34,36,37,41,47$, and 49 ) showed increases ranging from 0.9 to $10.7 \mathrm{ng} / \mathrm{L}$. The concentrations of NDEA and NDBA also significantly increased in 15 (ranging from 0.1 to $62.1 \mathrm{ng} / \mathrm{L}$ ) and 12 (ranging from 0.2 to $4.6 \mathrm{ng} / \mathrm{L}$ ) DWTPs, respectively. Different types of nitrosamines in finished waters have been detected and characterized in several other locations in North America, the United Kingdom, Australia, and Asia. In these studies, NDMA was the most commonly detected, and the concentrations were up to $18.3 \mathrm{ng} / \mathrm{L}$ in North America, up to $65 \mathrm{ng} / \mathrm{L}$ in Canada (Russell et al., 2012; Krasner et al., 2013; Uzun et al., 2015; Charrois et al., 2007; Zhao et al., 2008), up to $10 \mathrm{ng} / \mathrm{L}$ in Japan (Asami et al., 2009), and up to $35.7 \mathrm{ng} / \mathrm{L}$ in China (Wang et al., 2010, 2012). Compared to those surveys, NDEA and NDBA were also two dominant nitrosamines in finished waters in this study and previous reports of China (Wang et al., 2010, 2012). Further, a recent study showed that NDMA may only account for $\sim 5 \%$ of the estimated total nitrosamines (Dai and Mitch, 2013). In general, these results suggested that disinfection by chlorine or chloramine and pre-oxidation during drinking water treatment could produce nitrosamines due to the presence of precursors, which is consistent with previous reports (Chen and Young, 2008; Kemper et al., 2010; W.J. Zhou et al., 2009; Q. Zhou et al., 2009).

On the other hand, due to the higher concentrations of nitrosamines in source waters, the concentrations of NDMA decreased (ranging from 0.9 to $48.4 \mathrm{ng} / \mathrm{L}$ ) in the other 36 DWTPs. Decreases of NDEA and NDBA also were found in 24 (ranging from 0.7 to $42.6 \mathrm{ng} / \mathrm{L}$ ) and 26 (ranging from 0.2 to $4.6 \mathrm{ng} / \mathrm{L}$ ) DWTPs, and the removal efficiencies of the three nitrosamines were $12.6-100 \%, 18.3-100 \%$ and $23.9-100 \%$, respectively. Similar phenomena have also been reported in previous studies (Wang et al., 2011; Asami et al., 2009). In the 10 DWTPs with advanced treatment units $\left(\mathrm{O}_{3}+\right.$ BAC: DWTPs $12,16,14,18,19,20,21,26$, and 49; BAC + UV: DWTP 6), the relatively high FPs of NDMA, NDEA, and NDBA 
indicated that there were abundant precursors in source water samples. However, the concentrations of the three nitrosamines were mostly decreasing or stable in finished water samples after being treated by advanced treatment and disinfection (Fig. 3 and Supplementary Table C), suggesting that these advanced drinking water treatment units could effectively remove the precursors and discharges of nitrosamines in source water and control their formation in finished water. In general, pre-oxidation, biodegradation in sand/active carbon filters, and chlorination during disinfection might be responsible for the removal of nitrosamines (Wang et al., 2011; Krauss et al., 2009).

In terms of the regions (Fig. 5), high concentrations of nitrosamines were prevalent in south China, including South, Southeast, Southwest (the Yangtze River basin: DWTPs 44, 49, 50, 51, 52, 54, and the Pearl River basin DWTPs 17, 18, 19, 20), except for DWTP 4 (Northeast: Songhua River basin), the lower concentrations of nitrosamines were located in North, Northwest, and Middle of China. The profiling of nitrosamines accorded with the fact that the water quality of south China was more complicated than in north China. The unregulated discharge from a large number of township and village Enterprises in south China was a possible reason for the complicated water environment ( $\mathrm{Ng}, 2000$ ).

\subsection{Formation potential of the dominant nitrosamines}

The results of the nitrosamine-FPs in the 41 source waters for $24 \mathrm{~h}$ are presented in Fig. 3. The FPs of the dominant nitrosamines NDMA, NDEA, and NDBA for both in chlorination and chloramination prominently increased in many source water samples, with the highest values being $157.4,179$, and $149 \mathrm{ng} / \mathrm{L}$, respectively. All the largest concentrations observed in chloramination. Three nitrosamine-FPs in chloramination were in general higher than those found during chlorination, except for DWTPs 4, 24, 27, and 44. The relatively high concentrations of NDMA under chloramination in DWTPs $5,16,21,42$, and 54 were perhaps related to the contamination of source water, as indicated by the relatively high values of water-quality parameters $\left(\mathrm{NH}_{3}-\right.$ $\mathrm{N}, \mathrm{NO}_{3}^{2-}-\mathrm{N}, \mathrm{NO}_{2}^{-}-\mathrm{N}, \mathrm{DOC}$, and $\mathrm{UV}_{254}$; Supplementary Table $\mathrm{A}$ ), and the same results were observed for NDEA (DWTPs 17, 19, 42, 50, and 54) and NDBA (DWTPs 18, 19, 42, and 54). The concentrations of the three nitrosamines in many finished water samples were much lower than the FPs of source water under chloramination; this phenomenon could be attributed to the removal of precursors by different treatment units (i.e., pre-oxidation, ozonation, and biological activated carbon). The relatively low concentrations of the dominant nitrosamines in finished water from DWTP 6 were attributed to activated carbon filtration and the use of ultraviolet (UV) units (Jobb et al., 1994; Liang, 2002).

The large sample size with diverse water quality made it possible to interpret the effects of different factors on nitrosamine formation by

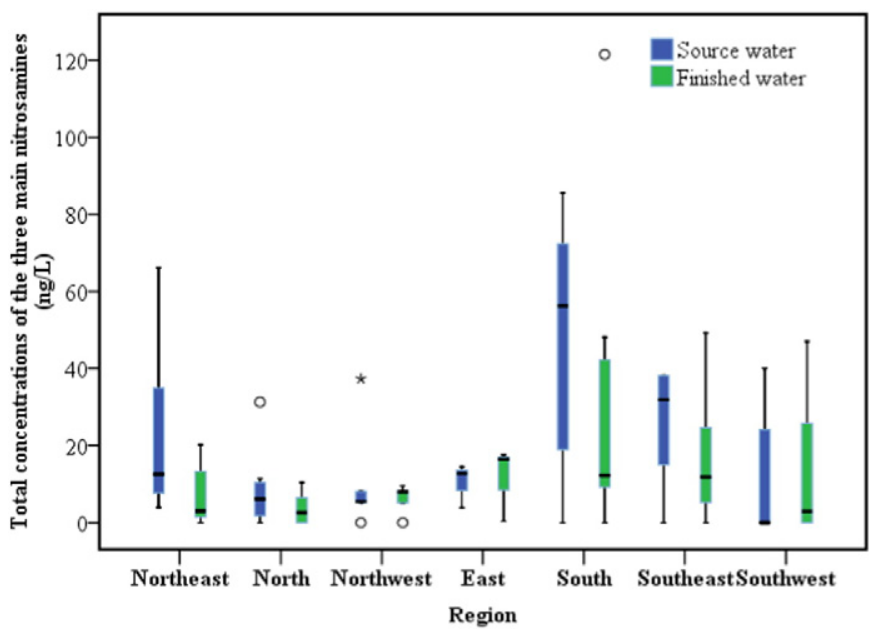

Fig. 5. Regional nitrosamine levels in China. employing principal component analysis (PCA). In this study, the relationship between the dominant water quality parameters $\left(\mathrm{NH}_{3}-\mathrm{N}\right.$, $\mathrm{NO}_{3}^{-}-\mathrm{N}, \mathrm{NO}_{2}^{-}-\mathrm{N}, \mathrm{DOC}$, and $\mathrm{UV}_{254}$ ) in source waters and total FPs of the three main nitrosamines (NDMA, NDEA and NDBA) under chloramination are illustrated in Fig. 6. The first two ordination axes explained $64.3 \%$ of total variability in nitrosamine-FPs data (Y axis) and $42.9 \%$ of water quality parameters ( $X$ axis), which indicated there was a strong linear relationship. Fig. 6 shows that the included angles between nitrosamine-FPs and the five water quality parameters were all acute angles, indicating a positive correlation. Among the five variables, nitrosamine-FPs were closely linked to ammonia values in source waters. Similar but weaker correlations were observed for the other four variables, listed here in decreasing order: $\mathrm{NO}_{2}^{-} \mathrm{N}, \mathrm{DOC}, \mathrm{UV}_{254}$, and $\mathrm{NO}_{3}^{-} \mathrm{N}$. Linear correlations also showed that a very weak correlation $\left(R^{2}=0.14\right)$ was observed between the sum FPs of the three nitrosamines and $\mathrm{NH}_{3}-\mathrm{N}$, poor correlations $\left(\mathrm{R}^{2}<0.10\right)$ were observed for DOC, SUVA $254, \mathrm{NO}_{3}^{2-} \mathrm{N}$, and $\mathrm{NO}_{2}^{-} \mathrm{N}$. This correlation was in accordance with the previous survey of Japan (Asami et al., 2009), which showed NDMA tended to be detected more frequently in samples that contained high concentrations of ammonia, nitrite, and nitrate. However, Charrois et al. (2007) showed that there was trend between higher DOC and SUVA values and detectable NDMA. Krasner et al. (2013) indicated that dissolved organic nitrogen (DON) may correlate with NDMA-FP; but Uzun et al. (2015) reported that there was only a weak correlation $\left(\mathrm{R}^{2}=0.27\right)$ between NDMA-FP and DON, and multiple linear regression analysis using DOC and log [sucralose] yielded a better correlation with NDMA FP $\left(R^{2}=0.53\right)$. In general, an accurate relationship may not be observed due to the lower concentration (ng/L level) of nitrosamines compared with the higher concentration levels of water quality parameters ( $\mathrm{mg} / \mathrm{L}$ level); further, the precursors of nitrosamines at lower concentration may significantly influence the nitrosamine-FPs, and which could not be reflected by the basic water quality parameters.

\subsection{Risks}

Nitrosamines, especially NDMA, NDEA, NDBA, were widely detected in DWTPs, which would pose a cancer risk to populations in drinking water. According to a previous study (Ma et al., 2012), we also estimated the cancer risk $\left(R_{\mathrm{i}}\right)$ due to the ingestion of drinking water containing NDMA, NDEA, and NDBA as quantified using Eq. (1).

$R_{i}=1 / 10000 \times \sum_{j=1}^{j=10000} C_{i j} \times$ Baseline $_{i}$

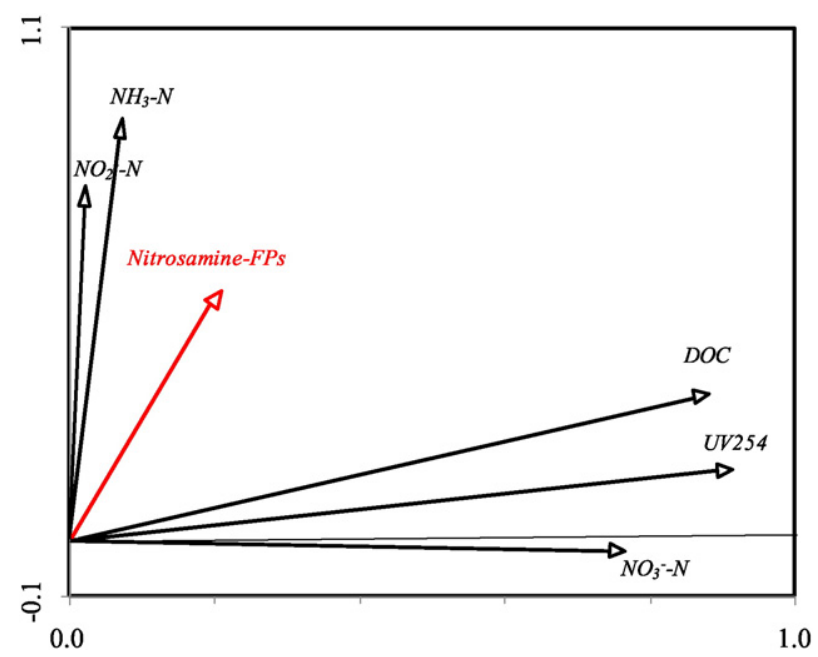

Fig. 6. PCA analyses between water quality variables and sum FPs of the three main nitrosamines. 
where the subscript $i$ represents the kind of chemical (NDMA, NDEA, and NDBA), $C_{* j}$ is the median or maximum concentration of NDMA, NDEA, and NDBA in finished water that was estimated by the bootstrap method (Matlab 2008b), $j$ is the sampling time in the bootstrap method, and Baseline is the drinking water unit risk of NDMA, NDEA, or NDBA. The unit risks of US EPA were used in this study: $1.4 \times 10^{-3} \operatorname{per}(\mu \mathrm{g} / \mathrm{L})$ for NDMA, $4.3 \times 10^{-3} \operatorname{per}(\mu \mathrm{g} / \mathrm{L})$ for NDEA, and $1.6 \times 10^{-4} \operatorname{per}(\mu \mathrm{g} / \mathrm{L})$ for NDBA (US EPA, 2007). The estimated median cancer risks for NDMA, NDEA, and NDBA in this study were $0.95 \times 10^{-5}, 2.02 \times 10^{-5}$, and $0.02 \times 10^{-5}$; and the estimated maximum cancer risks were $5.7 \times 10^{-5}, 2.95 \times 10^{-4}$, and $0.34 \times 10^{-5}$, respectively. The total median and maximum cancer risk of the three nitrosamines were determined to be $2.99 \times 10^{-5}$ and $35.5 \times 10^{-5}$. In addition, we estimated the cancer risk from the direct ingestion of source water containing NDMA, NDEA, and NDBA. The estimated median cancer risks for NDMA, NDEA, and NDBA in source water were $1.32 \times 10^{-5}, 2.80 \times 10^{-5}$, and $0.16 \times 10^{-5}$; and the estimated maximum cancer risks were $8.61 \times 10^{-5}, 1.83 \times 10^{-4}$, and $1.53 \times 10^{-5}$, respectively. The total median and maximum cancer risks of the three nitrosamines in source water were determined to be $4.28 \times 10^{-5}$ and $28.4 \times 10^{-5}$, which were higher than those in drinking water. This risk is higher than that $\left(4.12 \times 10^{-5}\right)$ in the Jialu River basin, where there has been an increasing incidence of digestive system cancer among local residents (Ma et al., 2012). Although there are different treatment processes in DWTPs, the removal rate of the total median cancer risk from source water to drinking water was only $30.1 \%$; further, the total maximum cancer risk from source water to drinking water increased, and the increasing rate was $24.8 \%$. Therefore, effective controls of these pollutants in DWTPs need further study.

\section{Conclusions}

This study investigated the occurrence of multiple nitrosamines in 54 source water and drinking water samples from 30 cities across China, and calculated the cancer risk of the dominant nitrosamines in drinking water samples. The main findings of this work include:

1. NDMA, NDEA and NDBA were the three major nitrosamines in source water and finished water samples of China with concentrations of up to $53.6 \mathrm{ng} / \mathrm{L}, 68.5 \mathrm{ng} / \mathrm{L}$, and $48.2 \mathrm{ng} / \mathrm{L}$, respectively, which were higher than those reported for the US and Canada. Further, the detectable ratios of the three dominant nitrosamines in source waters were higher than those in finished waters.

2. The statistical analysis showed nitrosamine-FPs in source waters had been closely influenced by ammonia. The advanced water treatment processes (i.e., $\mathrm{O}_{3}+\mathrm{BAC}$ ) could effectively control the nitrosamineFPs and remove nitrosamines from source waters.

3. The pollution of drinking water by nitrosamines may pose median and maximum risks of developing cancer of $2.99 \times 10^{-5}$ and $35.5 \times 10^{-5}$ to local populations. The current regulated treatment processes in DWTPs could not control the risk induced by nitrosamines. This study suggested that in spite of the much lower concentration levels in drinking water, the adverse health effects of nitrosamines should not be neglected, and further studies are required to evaluate the necessity of adopting regulations.

Supplementary data to this article can be found online at http://dx. doi.org/10.1016/j.scitotenv.2016.01.175.

\section{Acknowledgments}

This work was supported by the National Special Funding Project for Water Pollution Control and Management of China (2009ZX07419-001, 2008ZX07421-004) and the National Natural Science Foundation of China (No. 51208184).

\section{References}

Andrzejewski, P., Kasprzyk-Hordern, B., Nawrocki, J., 2008. Nnitrosodimethylamine formation during ozonation of dimethylamine-containing waters. Water Res. 42 (45), 863-870.

Asami, M., Oya, M., Kosaka, K., 2009. A nationwide survey of NDMA in raw and drinking water in Japan. Sci. Total Environ. 407 (11), 3540-3545.

Barrett, S., Hwang, C., Guo, Y.C., Andrews, S.A., Valentine, R., 2003. Occurrence of NDMA in drinking water: North American survey, 2001-2003. Proceedings of American WaterWorks Association annual conference and exhibition, Anaheim, CA (June, CD ROM).

Camel, V., Bermond, A., 1998. The use of ozone and associated oxidation processes in drinking water treatment. Water Res. 32 (11), 3208-3222.

Charrois, J.W.A., Boyd, J.M., Froese, K.L., Hrudey, S.E., 2007. Occurrence of N-nitrosamines in Alberta public drinking-water distribution systems. J. Environ. Eng. Sci. 6, 103-114

Chen, W.H., Young, T.M., 2008. NDMA formation during chlorination and chloramination of aqueous diuron solutions. Environ. Sci. Technol. 42 (4), 1072-1077.

Choi, J., Valentine, R.L., 2003. N-Nitrosodimenthylamine formation by free-chlorineenhanced nitrosation of dimethylamine. Environ. Sci. Technol. 37, 4871-4876.

Dai, N., Mitch, W.A., 2013. Relative importance of N-nitrosodimethylamine compared to total N-nitrosamines in drinking waters. Environ. Sci. Technol. 47 (8), 3648-3656.

Eichholzer, M., Gutzwiller, F., 1998. Dietary nitrates, nitrites, and N-nitroso compounds and cancer risk: a review of the epidemiologic evidence. Nutr. Rev. 56 (4 Part 1), 95-105.

Feng, D., Wang, H., Cheng, X., Wang, J., Ning, L., Zhou, Q., Zhou, Y., Yang, Q., 2009. Detection and toxicity assessment of nitrosamines migration from latex gloves in the Chinese market. Int. J. Hyg. Environ. Health 212 (5), 533-540.

Hartmetz, G., Slemrova, J., 1980. Detection of volatile nitrosamines in waste water from chemical plants by combined capillary gas chromatography-mass spectrometry. Bull. Environ. Contam. Toxicol. 25 (1), 106-112.

International Agency for Research on Cancer (IARC), 1978. IARC monographs on the evaluation of the carcinogenic risk of chemicals to humans. Some N-nitroso Compounds vol. 17. IARC Press, Lyon, France.

Jobb, D.B., Hunsinger, R.B., Meresz, O., Taguchi, V., 1994. Removal of Nnitrosodimethylamine from the Ohsweken (six nations) water supply final report. Ontario Ministry of Environment and Energy, Queen's Printer for Ontario.

Jurado-Sanchez, B., Ballesteros, E., Gallego, M., 2010. Screening of N-nitrosamines in tap and swimming pool waters using fast gas chromatography. J. Sep. Sci. 33 (4-5), 610-616.

Kemper, J.M., Walse, S.S., William, M.A., 2010. Quaternary amines as nitrosamine precursors: a role for consumer products? Environ. Sci. Technol. 44 (4), 1224-1231.

Krasner, S.W., Mitch, W.A., McCurry, D.L., Hanigan, D., Westerhoff, P., 2013. Formation, precursors, control, and occurrence of nitrosamines in drinking water: A review. Water Res. 47, 4433-4450.

Krauss, M., Longree, P., Dorusch, F., Ort, C., Hollender, J., 2009. Occurrence and removal of N-nitrosamines in wastewater treatment plants. Water Res. 43 (17), 4381-4391.

Liang, S., 2002. Photolysis and advanced oxidation processes for NDMA removal from drinking water. Presentation at the Fourth Symposium in the Series on Groundwater Contaminants: Perchlorate and NDMA in Groundwater: Occurrence, Analysis and Treatment. Groundwater Resources Association of California, Baldwin Park, CA (April 17).

Ma, F.J., Wan, Y., Yuan, G.X., Meng, L.P., Dong, Z.M., Hu, J.Y., 2012. Occurrence and source of nitrosamines and secondary amines in groundwater and its adjacent Jialu river basin, China. Environ. Sci. Technol. 46 (6), 3236-3243.

Mitch, W.A., Sharp, J.O., Trussell, R.R., Valentine, R.L., Alvarez Cohen, L., Sedlak, D.L., 2003. $\mathrm{N}$-nitrosodimethylamine (NDMA) as a drinking water contaminant: a review. Environ. Eng. Sci. 20 (5), 389-404.

$\mathrm{Ng}$, S.L., 2000. Township and village enterprises and rural environment in China. China Rev. 529-551.

Pehlivanoglu-Mantas, E., Hawley, E.L., Deeb, R.A., Sedlak, D.L., 2006. Formation of nitrosodimethylamine (NDMA) during chlorine disinfection of wastewater effluents prior to use in irrigation systems. Water Res. 40 (2), 341-347.

Planas, C., Palacios, O., Ventura, F., Rivera, J., Caixach, J., 2008. Analysis of nitrosamines in water by automated SPE and isotope dilution GC/HRMS-occurrence in the different steps of a drinking water treatment plant, and in chlorinated samples from a reservoir and a sewage treatment plant effluent. Talanta 76 (4), 906-913.

Qian, Y.C., Wu, M.H., Wang, W., Chen, B.B., Zheng, H., Krasner, S.W., Hrudey, S.E., Li, X.F., 2015. Determination of 14 nitrosamines at nanogram per liter levels in drinking Water. Anal. Chem. 87, 1330-1336.

Rodgers, N., 1997. Preliminary testing for control of DBPs in Cleveland. J. Am. Water Works Assoc. 89 (8), 78-87.

Russell, C.G., Blute, N.K., Via, S., Wu, X., Chowdhury, Z., 2012. Nationwide assessment of nitrosamine occurrence and trends. J. Am. Water Works Assoc. 104, 205-217.

Schmidt, C.K., Brauch, H.J., 2008. N, N-dimethylsulfamide as precursor for Nnitrosodimethylamine (NDMA) formation upon ozonation and its fate during drinking water treatment. Environ. Sci. Technol. 42, 6340-6346.

Sedlak, D.L., Deeb, R.A., Hawley, E.L., Mitch, W.A., Durbin, T.D., Mowbray, S., Carr, S., 2005 Sources and fate of nitrosodimethylamine and its precursors in municipal wastewater treatment plants. Water Environ. Res. 77 (1), 32-39.

Susan, D.R., Alfred, D.T., Chaim, R.A., Ludmila, G., Inna, P., Olga, J., Victor, G., McKague, A.B., Michael, J.P., Elizabeth, D.W., 2003. Tribromopyrrole, brominated acids, and other disinfection byproducts produced by disinfection of drinking water rich in bromide. Environ. Sci. Technol. 37 (17), 3782-3793.

Thilen, M., Shishoo, R., 2000. Optimization of experimental parameters for the quantification of polymer additives using SFE/HPLC. J. Appl. Polym. Sci. 76 (6) 938-946. 
US EPA, 2007. United States Environmental Protection Agency IRIS database. http://www. epa.gov/ncea/iris/.

Uzun, H., Kim, D., Karanfil, T., 2015. Seasonal and temporal patterns of NDMA formation potentials in surface waters. Water Res. 69, 162-172.

Verna, L., Whysner, J., Williams, G.M., 1996. Nnitrosodiethylamine mechanistic data and risk assessment: bioactivation, DNA-adduct formation, mutagenicity, and tumor Initiation. Pharmacol. Ther. 71 (1-2), 57-81.

Wang, W.F., Hu, J.Y., Yu, J.W., Yang, M., 2010. Determination of N-nitrosodimethylamine in drinking water by UPLC-MS/MS. J. Environ. Sci. 22 (10), 1508-1512.

Wang, W.F., Ren, S.Y., Zhang, H.F., Yu, J.W., Hu, J.Y., Yang, M., 2011. Occurrence of nine nitrosamines and secondary amines in source water and drinking water: potential of secondary amines as nitrosamine precursors. Water Res. 45, 4930-4938.

Wang, C.K., Zhang, X.J., Wang, J., Chen, C., 2012. Detecting N-nitrosamines in water treatment plants and distribution systems in China using ultra-performance liquid chromatography-tandem mass spectrometry. Front. Environ. Sci. Eng. 6 (6), 770-777.
Zhao, Y., Boyd, J.M., Woodbeck, M., Andrews, R.C., Qin, F., Hrudey, S.E., Li, X., 2008. Formation of $\mathrm{N}$-nitrosamines from eleven disinfection treatments of seven different surface waters. Environ. Sci. Technol. 42 (13), 4857-4862.

Zhou, W.J., Boyd, J.M., Qin, F., Hrudey, S.E., Li, X.F., 2009a. Formation of Nnitrosodiphenylamine and two new $\mathrm{N}$-containing disinfection byproducts from chloramination of water containing diphenylamine. Environ. Sci. Technol. 43 (21), 8443-8448.

Zhou, Q McCraven, S., Garcia, J., Gasca, M., Johnson, T A, Motzer, W.E., 2009b. Field evidence of biodegradation of $\mathrm{N}$-nitrosodimethylamine (NDMA) in groundwater with incidental and active recycled water recharge. Water Res. 43 (3), 793-805. 